\title{
A systematic review of using team-based learning in a pharmacokinetics course
}

\author{
Jutima Methaneethorn 1, Janthima Methaneethorn 2 \\ 1 Faculty of Education, Lampang Rajabhat University, Thailand \\ 2 Department of Pharmacy Practice, Faculty of Pharmaceutical Sciences, Naresuan University, Thailand
}

\author{
Keywords \\ Pharmacokinetics course \\ Pharmacy education \\ Team-based learning

\section{Correspondence} \\ Jutima Methaneethorn \\ Faculty of Education \\ Lampang Rajabhat University \\ Thailand \\ jutimam@gmail.com
}

\begin{abstract}
Background: This systematic review aimed to summarise an application of team-based learning (TBL) in pharmacokinetics courses, to compare the learning outcomes of TBL to that of traditional lecture-based courses, and to identify the benefits of using a TBL strategy in pharmacokinetics courses. Method: PubMed, Scopus, and ERIC EBSCO databases were systematically searched, and 191 non-redundant articles were retrieved. Of these, seven articles were included. Results: Implementation of a TBL in pharmacokinetic courses resulted in several positive results including higher examination grades, improvement in professionalism aspects such as altruism, accountability, and honesty. Student engagement, peer learning, and the development of transferable skills could also be observed. Despite these positive benefits, some challenges exist, such as an increase in initial workload for faculty members, preparation of appropriate assignments, and suitable strategy to facilitate students. Conclusion: Future TBL implementation should be critically designed to optimise faculties' workload and students' engagement to the course.
\end{abstract}

\section{Introduction}

Team-based learning (TBL) has been used widely in the business sector since the 1970s, and lately, has been spread into health sciences education. TBL has been proven to develop learning outcomes in colleges and schools of pharmacy including other health professions (Searle et al., 2003; Koles et al., 2005; Thompson et al., 2007; Clark et al., 2008; Parmelee et al., 2009; Koles et al., 2010; Bahramifarid et al., 2012; Farland et al., 2013; Fatmi et al., 2013; Ofstad \& Brunner, 2013; Cheng et al., 2014). TBL is a form of cooperative learning that allows learners to develop higher levels of learning according to Bloom's taxonomy. For a successful implementation of TBL, seven core elements should be incorporated including team formation, readiness assurance process (RAP), immediate feedback, sequencing of in-class problem solving, the four
'S' structure in developing team application exercises, incentive structure, and peer evaluation (Haidet et al., 2012).

As for team formation, groups of four to seven students with heterogeneous team composition is suggested to encourage greater participation and better exposure of participating students with peers (Farland et al., 2013). RAP is the process used for ensuring students' understanding of fundamental concepts, definitions, and foundational knowledge which are necessary for problemsolving. The purpose of RAP is to prepare students for upcoming activities. Immediate feedback helps students learn to quickly correct their misunderstanding of the content and move forward with a correct and strong foundation. In-class problem solving, and the four ' $S$ ' 
structures are components that relate to team application exercises. The purpose of the exercises is to build the basic level of understanding gained through the RAP and to provide opportunities for higher-order thinking including the development of soft skills such as teamwork and communication. Fundamentally, the exercises are built based on the four ' $S$ ' structure consisting of significant problem, same problem, specific answer choice, and simultaneous reporting. The incentive structure, another critical component, influences learner motivation, satisfaction, emotional intelligence including academic performance (Chung et al., 2009; Vasan et al., 2009; Deardorff et al., 2010; Koles et al., 2010; Borges et al., 2012; Haidet et al., 2012). Peer evaluation, the last element, helps students to develop professional skills and attitudes for being pharmacist practitioners in the future (Farland et al., 2013).

In pharmacy education courses are divided into modules and when applying TBL in a module, three phases should be executed i.e., pre-class preparation, RAP, and application of key concepts. Usually, the first phase occurs before the TBL session and is completed by students individually whereas the second and third phases happen during the class, and involve individuals, teams, and the entire class (Persky, 2012). TBL requires students to be familiar with the fundamental knowledge necessary for a particular learning module before coming into class. Thus, a preparation assignment such as literature articles, textbooks, handouts, and/or video lectures for each module should be planned and organised. The RAP phase is critical for the success of TBL implementation as it influences students' motivation. In this phase, students' performance will be evaluated using two tests: one for each student to complete at the beginning of each module, which is called iRAT, and another one for each team to discuss and choose the best answer, which is called tRAT. Once both tests are completed, tRATs will be collected, and the instructor must take a facilitator role to encourage discussions among the teams, provide feedback, and focus the class on fundamental and powerful learning concepts. In TBL literature, this facilitation is commonly referred to as 'mini-lecture'. The third phase is the application of key concepts through exercises. In TBL classrooms the highest level of learning occurs during these application exercises (Ofstad \& Brunner, 2013). The effective application exercises for team-based learning are usually built based on the four ' $S$ ' structure. After each application exercise is finished, the instructor has to provide guidance and feedback as part of the classroom discussion to ensure students' understanding of the main concepts before moving forward to the next exercise. Examples of TBL implementation in pharmacy education are described below.

Letassy and colleagues (2008) reported the use of TBL in the Pharm.D. (Doctor of Pharmacy) programme to increase students' ability in critical thinking and applying the information to solve patient cases. The use of this learning and teaching method provided the instructors the opportunity to shift in-class content delivery such as lecture to pre-class preparation which allowed more classroom time to be spent on problem-solving rather than content receiving. The study also confirmed that the time spent in the classroom was reduced by approximately $40 \%$ without negatively affecting students' learning outcomes. In addition, unit examination grades were reported to be improved and there was a greater percentage of students earning a course grade of $A$ compared to that of the previous year. No students earned a course grade of D or F. The authors also reported that team contribution and iRAT scores were significant predictive indicators for students' overall course performance. Conway and colleagues (2010) implemented TBL in a cardiovascular module for second year pharmacy students. Though the method was limited to $14.0 \%$ of the course, positive students' performance indicated by a course grade was observed. An increase in overall student and faculty satisfaction towards the use of TBL was also reported. However, two concerns were raised; The first concern was the complexity of the subject matter which made it difficult for students to learn all course materials independently; The second concern was students' initial resistance to self-directed learning since their learning styles were changing from passive attendance at lectures to being responsible for their own learning. Zingone and colleagues (2010) reported that using TBL in two ambulatory care elective courses resulted in significantly higher student grades. Findings from these studies suggest that TBL can be implemented successfully as a small component of the course, for an entire module, or as a learning and teaching method for an entire course.

Pharmacokinetics course is mathematically intense. Traditional pharmacokinetics teaching uses a lecturebased format and assigned coursework which may create obstacles to some students due to a lack of engagement, the crucial component for learning achievement when they face difficulties in mathematical solving (Persky \& Pollack, 2009). TBL approach is one of the strategies used to promote students' engagement in the course (Sharma et al., 2017) and has been widely used in pharmacy education. However, not many studies have been conducted regarding the use of TBL in pharmacokinetics courses. Thus, there is an exploratory need to expose the 
implementation of TBL in the course including its benefits and challenges to encourage more use of TBL in pharmacokinetics courses. This review aims to summarise the implementation of TBL in pharmacokinetics courses. The outcomes of TBL implementation, benefits and challenges of the approach are also discussed.

\section{Methods}

\section{Search strategy}

Three databases (PubMed, Scopus, and ERIC EBSCO) were systematically searched from their inception to October 2021. The search terms employed were: (pharmacokinetic OR 'clinical pharmacokinetic') AND ('team-based learning' OR TBL OR 'peer learning' OR 'team learning' OR 'mutual learning') AND ('learning outcome' OR knowledge OR skill OR attribute OR quality OR application). The reference lists of the identified articles were also reviewed for additional relevant studies.

\section{Inclusion and exclusion criteria}

Studies were eligible to be included in this systematic review if they were:

1) educational studies employing a TBL approach, and

2) studies conducted in pharmacokinetics courses.

While studies with the following characteristics were excluded from the review:

1) review articles or expert opinions,

2) studies published in languages other than English, and

3) studies implementing a TBL in courses other than pharmacokinetic courses.

Titles and abstracts of the non-redundant articles were screened independently by both authors. Subsequently, full-text articles were screened to include studies that met the inclusion criteria. Disagreements, if any, were discussed and resolved with consensus. The abstraction form for data extraction was designed by the first author and reviewed by the second author. The following information was independently extracted by both authors

1) objectives of the study, study design, instruments, and key findings of existing literature,

2) learning outcomes of TBL compared to that of the traditional lecture-based class, and
3) benefits and challenges of TBL implementation in pharmacokinetics course.

\section{Results}

\section{Study identification and characteristics}

Based on the systematic literature search 190 and 10 articles were retrieved from Scopus and PubMed databases, respectively. No study was identified from either ERIC EBSCO database or the reference lists. Nine duplicated articles were removed. Following the title and abstract screening, 134 studies were excluded since 79 articles were not relevant to the educational field and 55 studies were neither conducted with the TBL approach nor in the pharmacokinetic courses. This left 57 articles for the full-text screen, and 36 studies with the TBL approach were excluded as they were not conducted in pharmacokinetic courses. Moreover, seven studies conducted in a pharmacokinetic course, but TBL was not implemented were also excluded. The other seven studies were either book chapters or reviews, and thus they were also excluded. A total of seven studies met the prespecified criteria and were included in this systematic review. The included studies were published between 2010 and 2017. Details of study identification and reasons for study exclusion are presented in the PRISMA flow diagram (Figure 1).

\section{Characteristics of the included studies and their main objectives}

The number of TBL courses and the number of students in the courses ranged from one to two courses and 159-364 students per course, respectively. Students were divided into small groups of five to seven participants. However, four studies did not provide information on the number of students in each group (Persky \& Dupuis, 2014; Persky et al., 2015; Persky, 2015; Franklin et al., 2016). A summary of study characteristics (i.e. the number of TBL courses and students, materials for pre-class preparation, and activities in the TBL session) is summarised in Table I.

In terms of studies' objectives, three studies (Zingone et al., 2010; Persky, 2012; Persky \& Dupuis, 2014) aimed to assess the impact of TBL implementation on students' performance in pharmacokinetic courses. Moreover, Persky (2012) also assessed students' professionalism scores and attitudes towards the TBL approach. Each of the rest aimed to determine factors influencing interindividual variability in learning rate within a TBL environment (Persky et al., 2015), assess students' 


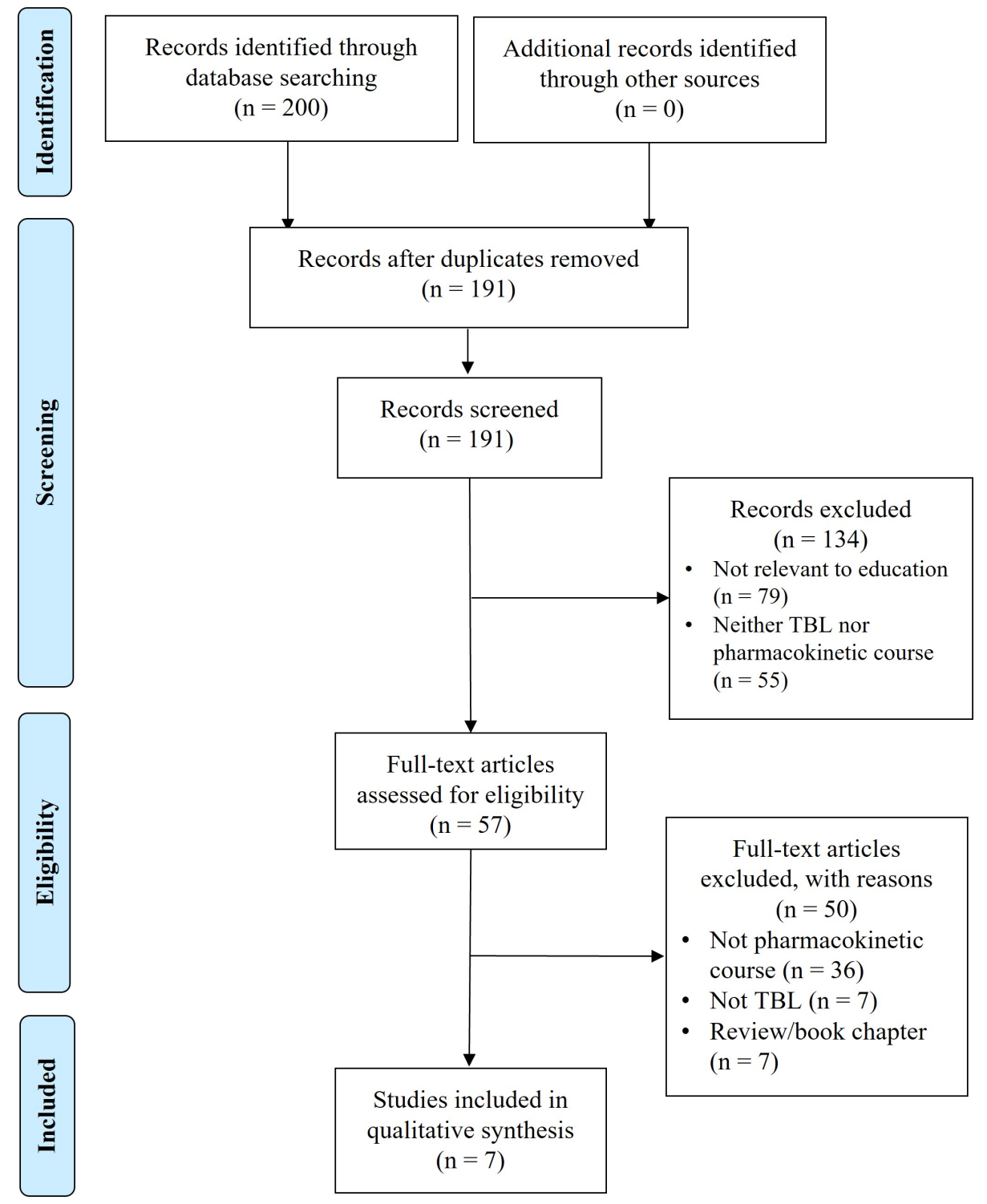

Figure 1: A PRISMA diagram of the study identification

preference on reading materials against multimedia materials used for a pre-class preparation in a TBL-format pharmacokinetic course (Persky, 2015), compare the effectiveness of two TBL approaches, face-to-face and online, that were employed to teach phenytoin pharmacokinetics (Franklin et al., 2016), and determine factors within the pre-class reading material that contribute to self-reported study time.

\section{Outcomes of the included studies}

For the impact of TBL implementation on students' performance, the results from Persky (2012) and Zgheib and colleagues (2010) were in agreement that group performance was better than individual performance.
Moreover, Zgheib and colleagues (2010) compared class performance on the summative quizzes to the previous year, and found that the mean score in the quizzes for the year that TBL was implemented was higher than the previous years, where the traditional lecture-based approach was used.

In terms of students' satisfaction and attitudes towards the TBL approach, it was reported that students' satisfaction was considerably high to a very high degree based on the mean score of five item Likert-like scale from eight questions (Zgheib et al., 2010). However, Persky (2012) assessed students' attitudes towards team learning based on five aspects including overall satisfaction with team experience, team impact on quality of learning, satisfaction with peer evaluation, team impact on clinical 
Table I: A summary of study characteristics

\begin{tabular}{|c|c|c|c|c|}
\hline No. & Reference & $\begin{array}{l}\text { No. of TBL } \\
\text { Courses }\end{array}$ & No. of Students & Groups of Students \\
\hline 1 & $\begin{array}{l}\text { Zgheib et } \\
\text { al., } 2010\end{array}$ & 2 & $\begin{array}{l}\text { 1.Drug Metabolism } \\
\text { and } \\
\text { Pharmacogenetics } \\
\text { course: } \mathrm{N}=81 \\
\text { 2.Pharmacokinetics/ } \\
\text { Pharmacodynamics } \\
\text { course: } \mathrm{N}=78\end{array}$ & $\begin{array}{l}12 \text { groups of five to } \\
\text { seven students each }\end{array}$ \\
\hline
\end{tabular}

2 Persky, 1 2012

3 Persky \& 1 Dupis,

2014

4 Persky et 1 al., 2015

5 Persky, 1 2015

\author{
1. Pharmacokinetics \\ Course (run \\ separately on two \\ campuses): \\ -University Campus \\ 1: $\mathrm{N}=143$ \\ -University Campus \\ 2: $\mathrm{N}=11$
}

\author{
26 groups of six
students each \\ 26 groups of six
students each

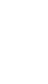

learning object, proble

sets, practice quizzes,

and old examinations

designated for self-

assessment purposes

only
Materials for Pre-class Activities in TBL Session

ation

drug metabolism and -Students formed their own groups and discussed the

same cases and questions and provided one set of

pharmacokinetics/

answers per group.

-Questions were formulated as either true/false or

multiple choice single best answer questions and all groups of students reported their answers

simultaneously.

-A discussion involving the whole class was

conducted.

-A wrap-up and an evaluation of the TBL session were performed.

-The facilitator assessed students' preparation using iRAT and gRAT.

-The facilitator reviewed the answers with the class and clarified the misunderstand-ing concept relating to the test.

-Students negotiated with their instructor about the contribution of iRAT and gRAT (iRAT $<=60.0 \%$, final quiz score and gRAT<= 4.0\%).

-All groups of students applied foundational concepts with patient cases through three to six corresponding questions.

-The facilitator reviewed each case and its related question with the entire class. Then, all groups of students considered available information and selected the best answer.

-The discussion was conducted involving the whole class.

An instructor-developed For the first two years

e-book and animated $\quad-$ In the first 14 weeks of the semester, students module prepared before class and were held accountable for the preparation; class time was used for cases.

-The last one to two weeks were used for capstone cases and review.

-The assessment was five quizzes, six cases, and two examinations.

\section{For the last year}

-In the first nine weeks of the semester, TBL was used to cover all materials.

-The last four to five weeks were used for a case review.

-The assessment was five quizzes, ten cases, and one examination.

-Five TBL modules were spread across the first 9 weeks of the course.

-The last seven weeks were used for an integrated pharmacokinetic case review.

-The assessment was four interim cumulative assessments and a cumulative final examination. -Students were given learning objectives for the instructor-developed study material.

-5 IRATs were used to assess students' preparation. -Students were asked to indicate their preferences for pre-class preparation using a bipolar scale with each format as anchors.

-Students were asked to comment on why they preferred one format over another in an openresponse question. 
Table I: A summary of study characteristics (continued).

\begin{tabular}{|c|c|c|c|c|c|c|}
\hline No & Reference & $\begin{array}{l}\text { No. of TBL } \\
\text { Courses }\end{array}$ & No. of Students & $\begin{array}{l}\text { Groups of } \\
\text { Students }\end{array}$ & $\begin{array}{l}\text { Materials for Pre- } \\
\text { class Preparation }\end{array}$ & Activities in TBL Session \\
\hline 6 & $\begin{array}{l}\text { Franklin et } \\
\text { al., } 2016\end{array}$ & 1 & $\begin{array}{l}\text { Pharmacokinetics course } \\
\text {-Online cohort: } \mathrm{N}=222 \\
\text {-Face-to-face cohorts: } \mathrm{N} \\
=70\end{array}$ & $\begin{array}{l}\text { Online Cohort } \\
\text {-four break-out } \\
\text { rooms with five } \\
\text { to seven learners } \\
\text { each ( } \mathrm{N}=222 \text { ) } \\
2 \text { Face-to-face } \\
\text { Cohort } \\
\text {-six tables with } \\
\text { five to six } \\
\text { learners per } \\
\text { table ( } \mathrm{N}=34 \text { ) } \\
\text {-six tables with } \\
\text { six learners per } \\
\text { table }(\mathrm{N}=36)\end{array}$ & No information & $\begin{array}{l}\text { Virtual TBL session } \\
\text {-Adobe Connect and Sakai LMS were used as a platform for a virtual class. The } \\
\text { main meeting room was created for the large room facilitations and breakout } \\
\text { rooms were created for tRAT and patient case team-discussions. } \\
\text {-iRAT and tRAT were created in Test \& Quizzes, Sakai quiz tool. } \\
\text {-Sign-up and scheduling occurred a minimum of two weeks prior to the online } \\
\text { session with available dates and time for learning activities. } \\
\text {-Learners were asked to participate in a practice session the day before the } \\
\text { first TBL activity to get used to the technology. } \\
\text {-Learners were randomly put in teams and each team was assigned a breakout } \\
\text { room to participate in an iRAT and tRAT following by an application exercise. } \\
\text {-The facilitator could visit each breakout room to introduce the application } \\
\text { exercise and identify discussion themes to promote discussion among } \\
\text { breakout groups. } \\
\text { In-class TBL session } \\
\text {-Two folders were placed on each table, one with iRAT and tRAT inside, and } \\
\text { the other one with a practice case, three rounds of questions, and a set of } \\
\text { laminated letters (A, B, C, D, and E) for the table to hold up when teams were } \\
\text { asked to give the best answer to a question. } \\
\text {-Following the readiness tests, teams were asked to work on each of the } \\
\text { application exercises independently, discuss their perspec-tives, and } \\
\text { collaborate with other teams in a facilitated TBL format with faculty. }\end{array}$ \\
\hline 7 & $\begin{array}{l}\text { Persky \& } \\
\text { Hogg, } \\
2017\end{array}$ & 2 & $\begin{array}{l}\text { 1. Physiology course } \\
\text { 2. Pharmacokinetics } \\
\text { course } \\
\text { Number of students were } \\
\text { not provided in both } \\
\text { courses. }\end{array}$ & No information & $\begin{array}{l}\text { An instructor- } \\
\text { developed } \\
\text { reading material }\end{array}$ & $\begin{array}{l}\text {-Students were asked to record their study time preparing for the readiness } \\
\text { assurance procedure (RAP). } \\
\text {-Students completed the individual quiz. } \\
\text {-Students completed the quiz in their assigned teams. }\end{array}$ \\
\hline
\end{tabular}

Table II: A summary of studies implementing TBL in pharmacokinetic courses

No Reference Aim Methods/Design Measurements

1 Zgheib et To examine the Modified TBL method Students' satisfaction (eight questions

al., 2010 effect of the TBL using two case-based on a five base Likert-like scale) approach on discussions:

teaching -An easy drug

Individual right answers versus group

second-year cogenetics session questions)

medical $\quad-$ A more challenging

students' PK/PD session

satisfaction and

performance

2 Persky, To assess the

Five TBL modules with Quiz scores from the individual quiz

2012

impact of TBL in

a foundation three learning phases in each module: pre-

pharmacokinetic class preparation,

s course quiz was compared to the previous readiness assurance process, and in-class and clinical cases were conducted
Class performance on the summa-tive years scores $(2005-2006$ and 2006-2007)

(iRAT) and team quiz (gRAT)

Survey of the professionalism scores in Paired $t$-test of five aspects: excellence, respect, altruism, duty, accountability and honesty.

Survey of attitudes towards five aspects of team learning: overall satisfaction with team experience, team impact on quality of learning, satisfaction with peer evaluation, team impact on clinical reasoning ability, professional development End-of-course evaluations compared $t$-test between the TBL year and the previous year (smaller group) hoc test

pre-and post-

course survey

\section{Statistical analysis Outcomes}

Mann-Whitney non-parametric

Positive feedback with the mean score ranging from 1.21-1.72 for drug metabolism and pharmacogenetics session and 1.75-2.06 for PK/PD session

Z-test for the com- Group performance was better than individual parison of proportions of right answers performance for all questions, with seven out of 18 questions being statistically significantly different $(p<$ 0.05)

One-way ANOVA -An improvement over the previous year (the mean with Tukey's post scores were $47.0 \%$ in the year $2005-2006,58.0 \%$ in the year 2006-2007, and $75.0 \%$ in the year 2007-2008) -The mean score in the year 2007-2008 was significantly higher than the year 2005-2006 $(p<0.05)$ Significant improvement in gRAT over iRAT $(>90 \%$ versus $>80 \%, p<0.05$ )

-Significant improvement in the overall scores (mean change $=2.8, p<0.05$ )

-Significant improvement in altruism, accountability, and honesty aspects $(p<0.05)$

Paired $t$-test of $\quad-$ No significant changes in attitudes in any category ( $p$ pre- and post- $>0.05$ )

course survey -Overall satisfaction with team experience was nearly significant $(p=0.056)$

Significant improvement $(p<0.05)$ in some aspects: -The course content was related to course objectives -Encourage active student engagement - Course objectives and assessments were aligned -Individual assistance was provided when needed 
Table II: A summary of studies implementing TBL in pharmacokinetic courses (continued).

No Reference Aim

3 Persky \& To assess the Dupuis, impact of

2014 increased active learning strategies on student performance in a foundational and clinical pharmacokinetics course over an eight-

\section{For a clinical pharma-} cokinetic (C-PK) course: a transition from LAL to casebased learning $(\mathrm{CBL})$

4 Persky et To examine fac-

al., 2015 tors influencing the interindividual variability of learning rates within a TBL environment

\section{Methods/Design}

For a foundation pharmatransition from a lecture with active learning (LAL) format to recitation format (REC) using smaller groups of students to a TBL format$$
\text { based learning (CBL) }
$$

Learning curve generatio through the completion of 4 interim cumulative assessments and a $5^{\text {th }}$ cumulative final exam. year period

5 Persky, To study the 2015 effects of using multimedia material against reading material for pre-class preparation in a TBL-format pharmacokinetics course

6 Franklin et To compare the al., 2016 effectiveness of face-to-face and online TBL reading material and teaching methods used to teach completed individual phenytoin pharmacokinetics

7 Persky \& To examine the Hogg, relationship be2017 tween instructordeveloped reading material and pre-class preparation time for readiness assurance process (RAP) in a TBL course (pharmacokinetics and physiology) (grades, standardized examcokinetics (F-PK) course: a -Two types of pre-class materials were provided prior to the TBL module i.e., animated module -At the end of the semester students rated their preference for pre-class

materials using a bipolar scale

-One online cohort and two -Comparison of IRAT and tRAT face-to-face cohorts (Tampa obtained from an online TBL

and Las Vegas) of pharmacy cohort and two face-to-face TBL students. -Students in all cohorts readiness tests (iRATs) and

\section{Measurements}

Examination performance in the

C-PK course comparing

between three-course formats:

1.F-PK: LAL, C-PK: CBL

F-PK: REC, C-PK: CBL

3.F-PK: TBL, C-PK: CBL

The first format was used as a control.

Examination performance in the C-PK course comparing CBL to $\mathrm{LAL}$

Relationship between examination score and course evaluation score

Covariates influencing

interindividual variability of learning rates including: 1.prior academic experience ination scores)

2.study skills (number of practice problems, study strategies, motivation)

3.personality traits and attitudes (introversion/extraversion, self-views of intelligence, attitudes towards team learning) were assessed 1.Students' preference on the pre-class preparation.

1.Qualitative analysis on the students' test (iRAT) between methods of preference of prepreparation. class preparation 2. Kruskal-Wallis test to compare the median iRAT scores across preferences One-way ANOVA cohorts

-Teamwork survey team readiness tests (tRATs) as well as a self-assessment survey

- Self-report from students about the amount of time spent on studying for RAP in pharmacokinetics and physiology courses

- To determine factors within the pre-class reading material that contribute to self-reported study time alysis regression

\section{Statistical analysis Outcomes} format (effect size: $0.78,95 \% \mathrm{Cl}$ : 0.58-0.97, $p<0.001$ )

in F-PK -A moderate increase in C-PK score of REC format over LAL format (effect size: $0.51,95 \% \mathrm{Cl}: 0.32-0.70, p$ $<0.001$ )

-A small increase in C-PK score of TBL format over REC format (effect size: $0.27,95 \% \mathrm{Cl}: 0.14-0.40, p<$ 0.001)

-A significant moderate increase in examination scores of CBL (87.7) over LAL (85.9), $p<0.01$

-For F-PK course: $r=-0.682, p<0.05$

-For C-PK course: $r=0.230$

1.Initially, a higher grade point average (GPA) was significantly associated with faster learning rates; however, after personality traits were added, the significant effect disappeared

2.No significant effect of practice or motivation components on learning rate, but metacognitive selfregulation (i.e., planning, monitoring, regulating of cognition and learning) partially explained variability in learning rate $(p<0.05)$

3.Introversion/extroversion did not influence performance in a TBL environment, though lower team learning preference was observed in introverts.

1.About $66.7 \%$ of the students preferred reading materials over the animated modules. 2.A significantly higher iRAT score on the quizzes was observed in students who preferred the reading materials over the animated modules $(p=0.05)$ better than the two face-to-face cohorts $(p<0.05)$. -For iRAT, the face-to-face cohort from Las Vegas performed best $(p<0.01)$.

-tRATs scores were higher than iRATs scores, but the iRAT scores were more predictive of knowledge retention than the tRAT scores (from the bonus points in the final examination).

-Positive interactions among teams in all cohorts. -TBL was effective for a pharmacokinetics course in both face-to-face and online classes.

-Correlation an- $\quad 3.2$ hours on average used in preparation for a -Multilevel linear - The average ratio of self-report study time to class time on each topic was 36 minutes of pre-class study to one hour class time

Predictors for self-reported study time - Positive predictors: word count and number of assessments $(p<0.001)$ - Negative predictors: topic difficulty and number of figures $(p<0.001)$ 
reasoning ability, and professional development, and found that no significant changes $(p>0.05)$ in any category of attitudes were observed. Moreover, five aspects of professionalism were evaluated: excellence, respect, altruism, duty, accountability, and honesty; and of these, significant improvement was reported for the altruism, accountability, and honesty aspects $(p<0.05)$ (Persky, 2012).

Further, Persky and colleagues (2015) determined whether three categories of covariates (prior academic experience, study skills, and personality traits and attitudes) significantly influence the interindividual variability in learning rates within a TBL environment. The results indicated that only metacognitive self-regulation (i.e., planning, monitoring, regulating of cognition and learning) partially explained variability in learning rate $(p<$ 0.05). While personality traits such as introversion/ extroversion did not have an impact on student performance in a TBL environment, they might impact student attitudes about the course environment.

Preference on the two types of pre-class materials in a TBL-format pharmacokinetics course (reading materials and animated modules) were also explored (Persky, 2015). The author found that approximately $66.7 \%$ of the students preferred reading materials over the animated modules. Moreover, two types of TBL methods (face-toface and online) were also compared and the results indicated that TBL was effective for a pharmacokinetics course in both face-to-face and online formats (Franklin et al., 2016). Finally, Persky and Hogg (2017) identified that word count and the number of assessments were positive predictors, whereas, topic difficulty and the number of figures were negative predictors significantly influenced self-reported study time used in a TBL course $(p<0.001)$. The methods, statistical analysis and outcomes of each study are summarised in Table II.

\section{Discussion}

Pharmacokinetics involves the application of mathematical principles to explain drug concentration versus time data in animals and humans. In pharmacokinetics the crucial competencies are the ability to calculate dosing regimens, recover specific parameters, and apply pharmacokinetics concepts with the support of mathematical calculations. A traditional pharmacokinetics classroom uses a lecture-based approach; however, this approach does not fit well with how adults learn.
Authentic problem-solving is an instructional technique that is well-supported to be able to promote critical thinking, collaboration, and communication; these are all components that can be found in TBL (Persky, 2012). Pharmacy educators and current accreditation standards believe that the main skills desirable for future pharmacists are information processing, problem-solving, decision making, communication, work planning, and organisation. These beliefs are congruent with a survey conducted by the National Association of Colleges and Employers (Persky, 2012).

To the authors knowledge, this is the first systematic review of TBL implementation in pharmacokinetics courses. It will discuss three aspects of using of TBL in pharmacokinetics courses: the implementation, the benefits, and the challenges. According to this review, TBL was proven to be more effective compared to other learning and teaching methods used in pharmacokinetics courses such as lecture-based approach and small group learning method, e.g., tutorials, seminars, workshops, project-based learning, recitation (Persky, 2012, 2014). This is congruent with results from other studies (Zgheib et al., 2010; Persky \& Dupuis, 2014). TBL can be conducted in both face-to-face and online classes and it was effective in both (Franklin et al., 2016). When implementing TBL, three stages were usually performed: pre-class preparation, RAP in which iRAT and tRAT were used to assess students' performance, and wrap-up/discussion. In the pre-class preparation phase, instructors had to prepare learning materials for students which appeared in many forms, e.g., PowerPoint presentations, an e-book, and animated multimedia. And, when students were in class, they had to perform iRAT individually followed by teamwork for tRAT. Then, the class was finished with a wrap-up/discussion session involving the whole class. Many benefits of TBL implementation in pharmacokinetics courses can be drawn from the reviewed studies. For example, higher examination scores (Zgheib et al., 2010; Persky, 2012; Persky \& Dupis, 2014) and professionalism (A. M. Persky, 2012) were reported. Moreover, positive feedback from students' satisfaction surveys were also identified (Zgheib et al., 2010). Though no significant changes in attitudes were observed from Persky's study (2012), Tweddell and colleagues (2016) assessed faculty perceptions and experiences of TBL implementation across pharmacy curriculum and found that TBL implementation enhanced student engagement, peer learning, and development of transferable skills. It also increased faculty enjoyment of teaching (Tweddell et al., 2016). The non-significant changes in attitudes from Persky's study could be related to students' perception of learning. Students in the TBL felt they missed out on 
learning to a greater extent compared with the smallergroup format cohort, even though they could get more individual assistance in the TBL format. This lower extent of perceived learning might better relate to the role peers play in the learning process. Some students favour instructors as experts while some of them accept peers as experts (Persky, 2012). Given that TBL relies deliberately on peer instruction, some students might feel they are not getting adequate learning experiences. To improve student attitude towards peer instruction, the importance and benefits of peer learning could be introduced in the TBL format. However, some challenges still exist from the review of the literature. One of the most important and challenging tasks is an investment in faculty development and time for resource preparation since TBL is a studentcentred approach, and thus, faculty skills set for facilitating learner-centred class is required (Tweddell et al., 2016). The second challenge is the preparation of the appropriate assignments and the writing of effective application exercises. Further investigation is needed for the refinement of the exercises aiming to develop other noncontent skills such as problem-solving (Zgheib et al., 2010; Persky, 2012). The third challenge is the development of materials for pre-class preparation. The materials must be efficient and effective to optimise student preparation since out-of-class time management is important for professional program in which students' time is limited. The self-pacing ability, the level of detail, the organisation, and the readability of text are crucial components that should be taken into account when developing the materials (Persky, 2015; Persky \& Abigail Hogg, 2017). Another challenge is the investigation of potential factors that contribute to interindividual differences in the TBL environment since the evidence showed that increasing student accountability might affect students' attitudes towards the use of TBL (Persky \& Dupuis, 2014). Also, for students with introverted personality types, the TBL approach seemed to be less preferred (Persky, 2015). The last challenge is the need for more studies of technological impact on learning compared to other methods as so far, two studies (Persky, 2012; Persky, 2015) have been conducted regarding this issue.

\section{Conclusion}

This systematic review identified that the implementation of TBL in pharmacokinetics courses could improve student learning and professionalism such as altruism, accountability, and honesty. Transferable skills could also be developed. Faculty enjoyment in teaching was also increased in TBL classes. Though the initial workload was found to be increased, it was subsequently informed to be optimised. However, challenges for TBL implementation in pharmacokinetics courses do exist, e.g. an investment in faculty development and time for resource preparation, the preparation of appropriate assignments and the refinement of application exercises, the development of effective and efficient materials for pre-class preparation.

\section{Competing interests}

The authors declare no competing interests.

\section{References}

Bahramifarid, N., Sutherland, S., \& Jalali, A. (2012). Investigating the applications of team-based learning in medical education. Education in Medicine Journal, 4(2). https://doi:10.5959/eimj.v4i2.3

Borges, N.J., Kirkham, K., Deardorff, A.S., \& Moore, J.A. (2012). Development of emotional intelligence in a team-based learning internal medicine clerkship. Medical teacher, 34(10), 802-806. https://doi.org/10.3109/0142159X.2012.687121

Cheng, C.-Y., Liou, S.-R., Tsai, H.-M., \& Chang, C.-H. (2014). The effects of team-based learning on learning behaviors in the maternal-child nursing course. Nurse education today, 34(1), 25-30. https://doi.org/ 10.1016/j.nedt.2013.03.013

Chung, E.-K., Rhee, J.-A., \& Baik, Y.-H. (2009). The effect of team-based learning in medical ethics education. Medical teacher, 31(11), 1013-1017. https://doi.org/10.3109/01421590802590553

Clark, M.C., Nguyen, H.T., Bray, C., \& Levine, R.E. (2008). Team-based learning in an undergraduate nursing course. Journal of Nursing Education, 47(3), 111-117. https://doi.org/ 10.3928/01484834-20080301-02

Conway, S.E., Johnson, J.L., \& Ripley, T.L. (2010). Integration of teambased learning strategies into a cardiovascular module. American Journal of Pharmaceutical Education, 74(2), 35. https://doi.org/ 10.5688/aj740235

Deardorff, A.S., Moore, J.A., Borges, N.J., \& Parmelee, D.X. (2010). Assessing first year medical student attitudes of effectiveness of team-based learning. Medical Science Educator, 20(2), 67-72.

Farland, M.Z., Sicat, B.L., Franks, A.S., Pater, K.S., Medina, M.S., \& Persky, A.M. (2013). Best practices for implementing team-based learning in pharmacy education [Review]. American Journal of Pharmaceutical Education, 77(8). https://doi.org/10.5688/ ajpe 778177

Fatmi, M., Hartling, L., Hillier, T., Campbell, S., \& Oswald, A.E. (2013). The effectiveness of team-based learning on learning outcomes in health professions education: BEME Guide No. 30. Medical teacher, 35(12), https://doi.org/10.3109/0142159X.2013.849802 
Franklin, A.S., Markowsky, S., De Leo, J., Norman, S., \& Black, E. (2016). Using team-based learning to teach a hybrid pharmacokinetics course online and in class [Article]. American Journal of Pharmaceutical Education, 80(10), Article 171. https:// doi.org/10.5688/ajpe8010171

Haidet, P., Levine, R.E., Parmelee, D.X., Crow, S., Kennedy, F., Kelly, P.A., Perkowski, L., Michaelsen, L., \& Richards, B.F. (2012). Perspective: guidelines for reporting team-based learning activities in the medical and health sciences education literature. Academic Medicine, 87(3), 292-299. https://doi.org/10.1097/ACM. 0b013e318244759e

Koles, P., Nelson, S., Stolfi, A., Parmelee, D., \& DeStephen, D. (2005). Active learning in a year 2 pathology curriculum. Medical education, 39(10), 1045-1055. https://doi.org/10.1111/j. 1365-2929.2005.02248.x

Koles, P.G., Stolfi, A., Borges, N.J., Nelson, S., \& Parmelee, D.X. (2010). The impact of team-based learning on medical students' academic performance. Academic Medicine, 85(11), 1739-1745. https:// doi.org/10.1097/ACM.0b013e3181f52bed

Letassy, N.A., Fugate, S.E., Medina, M.S., Stroup, J.S., \& Britton, M.L. (2008). Using team-based learning in an endocrine module taught across two campuses. American Journal of Pharmacy Education, 72(5), 103. https://doi.org/10.5688/aj7205103

Ofstad, W., \& Brunner, L.J. (2013). Team-based learning in pharmacy education [Review]. American Journal of Pharmaceutical Education, 77(4). https://doi.org/10.5688/ajpe77470

Parmelee, D.X., DeStephen, D., \& Borges, N.J. (2009). Medical students' attitudes about team-based learning in a pre-clinical curriculum. Medical education online, 14(1), 4503. https://doi.org/ 10.3885/meo.2009.Res00280

Persky, A.M. (2012). The impact of team-based learning on a foundational pharmacokinetics course. American Journal of Pharmaceutical Education, 76(2), 31-31. https://doi.org/10.5688/ ajpe76231

Persky, A.M. (2015). Qualitative Analysis of Animation versus Reading for Pre-Class Preparation in a "Flipped" Classroom. Journal on Excellence in College Teaching, 26(1), 5-28.

Persky, AM., \& Dupuis, RE. (2014). An eight-year retrospective study in "flipped" pharmacokinetics courses. American Journal of Pharmaceutical Education, 78(10), 190-190. https://doi.org/10.5688/ ajpe7810190

Persky, A.M., Henry, T., \& Campbell, A. (2015). An exploratory analysis of personality, attitudes, and study skills on the learning curve within a team-based learning environment. American Journal of Pharmaceutical Education, 79(2), 20-20. https://doi.org/10.5688/ ajpe79220

Persky, A.M., \& Hogg, A. (2017). Influence of Reading Material Characteristics on Study Time for Pre-Class Quizzes in a Flipped Classroom. American Journal of Pharmaceutical Education, 81(6), 103-103. https://doi.org/10.5688/ajpe816103

Persky, A.M., \& Pollack, G.M. (2009). A hybrid jigsaw approach to teaching renal clearance concepts. American Journal of Pharmaceutical Education, 73(3), 49-49. https://doi.org/10.5688/ aj730349
Searle, N.S., Haidet, P., Kelly, P. A., Schneider, V.F., Seidel, C.L., \& Richards, B.F. (2003). Team learning in medical education: initial experiences at ten institutions. Academic Medicine, 78(10), S55-S58. https://doi.org/10.1097/00001888-200310001-00018

Sharma, A., Janke, K.K., Larson, A., \& Peter, W.S. (2017). Understanding the early effects of team-based learning on student accountability and engagement using a three session TBL pilot. Currents in Pharmacy Teaching and Learning, 9(5), 802-807. https:// doi.org/10.1016/j.cptl.2017.05.024

Thompson, B.M., Schneider, V.F., Haidet, P., Levine, R.E., McMahon, K.K., Perkowski, L.C., \& Richards, B. F. (2007). Team-based learning at ten medical schools: two years later. Medical education, 41(3), 250-257. https://doi.org/10.1111/j.1365-2929.2006.02684.x

Tweddell, S., Clark, D., \& Nelson, M. (2016). Team-based learning in pharmacy: The faculty experience [Article]. Currents in Pharmacy Teaching and Learning, 8(1), 7-17. https://doi.org/10.1016/j.cptl. 2015.09.008

Vasan, N. S., DeFouw, D. O., \& Compton, S. (2009). A survey of student perceptions of team-based learning in anatomy curriculum: Favorable views unrelated to grades. Anatomical sciences education, 2(4), 150-155. https://doi.org10.1002/ase.91

Zgheib, N.K., Simaan, J.A., \& Sabra, R. (2010). Using team-based learning to teach pharmacology to second year medical students improves student performance. Medical teacher, 32(2), 130-135. https://doi.org/10.3109/01421590903548521

Zingone, M.M., Franks, A.S., Guirguis, A.B., George, C.M., HowardThompson, A., \& Heidel, R. E. (2010). Comparing team-based and mixed active-learning methods in an ambulatory care elective course. American Journal of Pharmacy Education, 74(9), 160. https://doi.org/ 10.5688/aj7409160 